http://jmscr.igmpublication.org/home/ ISSN (e)-2347-176x ISSN (p) 2455-0450 crossref DOI: https://dx.doi.org/10.18535/jmscr/v10i2.15

\title{
Mutation Specific Antibodies for Immunohistochemical detection of Epidermal Growth Factor Receptor Mutations in Lung Adenocarcinomas
}

\author{
Authors \\ Dr Aswathy Shibu ${ }^{*}$, Dr Rajan $\mathbf{G}^{2}$, Dr Sathi $\mathbf{P} \mathbf{P}^{3}$ \\ ${ }^{1}$ Junior Resident, Department of Pathology, Govt. Medical College, Kozhikode, Kerala, India \\ ${ }^{2}$ Professor, Department of Pathology, Govt. Medical College, Kozhikode, Kerala, India \\ ${ }^{3}$ Professor and HOD, Department of Pathology, Govt. Medical College, Kozhikode, Kerala, India \\ *Corresponding Author \\ Dr Aswathy Shibu \\ Junior Resident, Department of Pathology, Govt. Medical College, Kozhikode, Kerala, India
}

\begin{abstract}
Introduction: EGFR over expression and mutation play an important role in the carcinogenesis of lung adenocarcinoma. The most common adenocarcinoma-associated EGFR mutations are in-frame deletions in exon 19 (E746_A750del) and the point mutation replacing leucine with arginine at codon 858 in exon 21 (L858R). Antibodies that specifically detect mutant EGFR protein by immunohistochemistry can be used to detect these specific mutations.

Objectives: 1) To find out the prevalence of EGFR mutations in lung adenocarcinoma patients using mutant specific immunohistochemical markers.

2) To assess the clinical and biological features associated with EGFR mutation.

Materials and Methods

Study Design: Descriptive Study

Study Population: All cases of Adenocarcinoma Lung diagnosed in the Department Of Pathology, Govt. Medical College, Kozhikode during the study period

Sample Size: 100

Results: Of the 100 cases, 88 were male (88\%) and 12 were female $(12 \%)$ with a mean age of 63 years. Out of 100 cases, 19 cases showed EGFR mutation. 14 patients (13 males; 1 female) showed positivity for del E746-A750 and 9 patients for L858R (9 male, 0 female). 4 patients showed positivity for both. EGFR mutation rate was higher in adenocarcinomas of lepidic and acinar subtypes than of other subtypes( $p<$ $0.05)$

Conclusions: In this preliminary study, mutation specific IHC was used for assessment of mutation status of EGFR.IHC methodology is a potentially useful tool to guide clinicians for targeted therapies where facilities for molecular analysis are not readily available.

Keywords: Adenocarcinoma, Epidermal growth factor receptor (EGFR), exon 19, exon 21, mutation specific antibodies for E746-A750 and L858R.
\end{abstract}

\section{Introduction}

Lung cancer is the most common type of cancer worldwide with an estimation of 1.82 million new cancer cases diagnosed. It is the leading cause of cancer related deaths $^{[1]}$. It is the commonest cancer and cause of cancer related mortality in men. 
Carcinoma lung can be broadly classified into Small cell lung and Non small cell carcinoma. Non small cell lung cancer (NSCLC) accounts for approximately $80 \%$ of all lung cancers. Adenocarcinoma and squamous cell carcinoma are the two major subtypes of non-small cell lung carcinoma.

Epidermal growth factor receptor (EGFR), is one of several somatic mutations, in NSCLC ${ }^{[2]}$, which is seen more frequently in certain population groups. This population group is classically described as Asian, non-smoking females with adenocarcinoma ${ }^{[3,4]}$. The interest in these mutations is due to the small molecule targeted therapies (such as erlotinib and gefitinib) available and in development, which can have significant prognostic significance $e^{[5,6]}$

There are many methods to detect the EGFR mutations. The most commonly used methodology is, direct sequencing of PCR products. The main drawbacks of this method are its low sensitivity (20-50\%) and the significant risk of contamination involved in handling post-PCR products. Recent advances in molecular techniques have enabled the development of more sensitive methods for detecting mutations with realtime quantitative PCR, using specific probes or amplified refractory mutation system (ARMSTM) technology. Most recently, the development of EGFR mutant-specific antibodies for immunohistochemistry (IHC) has presented a new method for the detection. Antibodies are available against the most common mutant forms of EGFR on EXON 19 and 21.

In our study, we aimed at determining the prevalence of these two EGFR mutations, using IHC specific antibodies among all adeno carcinomas diagnosed in our centre.

\section{Objectives}

1. To find out the prevalence of EGFR mutations in lung adenocarcinoma patients using mutant specific immunohistochemical markers.

2. To assess the clinical and biological features associated with EGFR mutation.

\section{Materials and Methods}

Type of study: Descriptive study

Study Period: 24 months; January 2017 to December 2018

Study Setting: Dept. Of Pathology, Government Medical College, Kozhikode

Sample Size: 100

Study Population: 100 adenocarcinoma lung patients diagnosed in Dept. of Pathology, Govt. Medical College Kozhikode during the study period Inclusion Criteria: All lung biopsy samples (Endo bronchial, Trucut, Transbronchial lung biopsies) of clinically and histologically diagnosed lung adenocarcinoma patients irrespective of age and gender received in dept. of Pathology, Govt. Medical College, Kozhikode

Exclusion Criteria: 1. All metastatic carcinomas 2. Those cases where biopsy material is inadequate for IHC studies

\section{Study Procedure}

- Approval from Ethics committee and the Research Board of the Institution was obtained.

- All cases clinically diagnosed as carcinoma of lung from the Department of Chest disease and which were diagnosed as Adenocarcinoma lung (TTF 1 positive cases) from the Department of Pathology was collected.

- The clinical history was collected from the case sheets as well as Pathology requisition forms.

- $\quad H \& E$ slides studied and histological sub typing done

- Paraffin embedded blocks of the same were taken, cut at 5 micrometre, IHC staining(using standardised procedure) was done with exon 19 deletion mutation antibody and one for exon 21 point mutation antibody ((Primary antibodies used: delE746-A750 mutation specific monoclonal antibody (6B6) and L858R mutation specific monoclonal antibody (43B2);Cell signalling technology, Danvers, MA,USA)

Intensity of staining was scored as following: $0=$ no staining; $1+=$ faint membrane and/or cytoplasmic staining in $>10$ per cent of tumour cells in $\mathrm{x} 40$ objective magnification; $2+=$ moderate membrane 
and/or cytoplasmic staining in $\mathrm{x} 10$ to $\mathrm{x} 20$ objective magnification; $3+=$ strong membrane and/or cytoplasmic staining $\mathrm{x} 2$ to $\mathrm{x} 4$ objective magnification.

Scores $1+, 2+$ and $3+$ were considered as positive cases.

Data Management and Analysis: The data was entered in Microsoft Excel and Statistical analysis was done using SPSS 18 software. Chi square test was used and a $\mathrm{p}$ value $<0.05$ was considered as statistically significant.

\section{Results}

- The present study was carried out to analyse the two common EGFR mutations (exon 19 deletion and exon 21 point mutation) in lung adenocarcinoma by immunohistochemistry using mutant specific antibodies.

- Among the 100 cases studied, 88(88\%) were males and $12(12 \%)$ were females. The mean age of cases was 63 years.

Table 1: Age group wise distribution of the cases

\begin{tabular}{|l|c|c|}
\hline Age group & Frequency & Percentage \\
\hline $40-49$ & 4 & $4 \%$ \\
\hline $50-59$ & 27 & $27 \%$ \\
\hline $60-69$ & 46 & $46 \%$ \\
\hline $70-79$ & 19 & $19 \%$ \\
\hline $80-89$ & 4 & $4 \%$ \\
\hline
\end{tabular}

- $56 \%$ of the patients were smokers and $44 \%$ were never smokers.

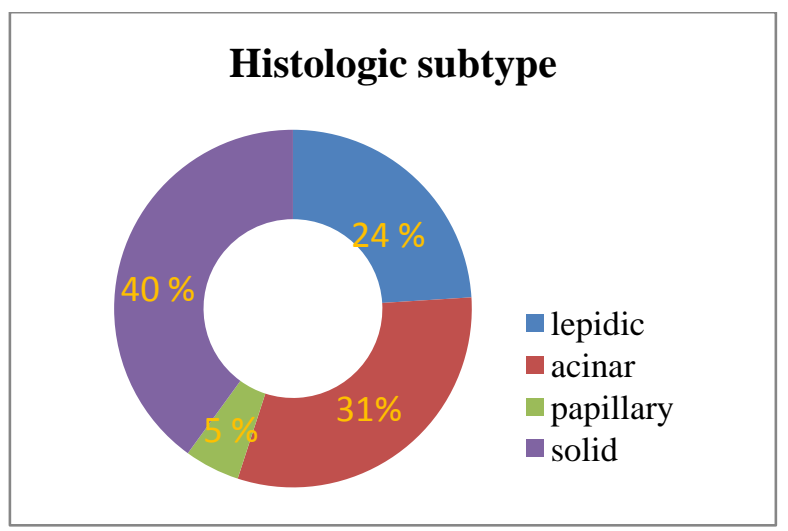

Figure 1: Distribution of cases on the basis of Histological Subtype of the tumor

Table 2: Stage wise distribution of cases

\begin{tabular}{|l|c|c|}
\hline Stage & No. of cases & Percentage \\
\hline 2 & 22 & $22 \%$ \\
\hline 3 & 68 & $68 \%$ \\
\hline 4 & 10 & $10 \%$ \\
\hline
\end{tabular}

Table 3: EGFR IHC expression among the cases

\begin{tabular}{|c|c|}
\hline \multicolumn{2}{|c|}{$\begin{array}{l}\text { Total no. of cases: } 100 \\
\text { Positive cases: } 19 \\
\text { Cases with double mutation: } 4\end{array}$} \\
\hline Totalmutations & 23 \\
\hline Exon 19 Deletion & $14 / 23(61 \%)$ \\
\hline Exon 21 point mutation & $9 / 23(39 \%)$ \\
\hline
\end{tabular}

\section{Discussion}

In our study, $19 \%$ of the patients were found to harbor an EGFR mutation (exon 19 Del=14 and exon 21 mutation=9) among the 100 patients tested. 4 patients had concurrent mutation in these exons.

Gaur P et al, in their study among North Indian lung cancer patients, obtained a prevalence of $34 \%$ (73) using mutant specific antibodies by immunohistochemistry. $79.17 \%$ of the mutations were in exon 19 and $20.83 \%$ in exon 21.In our study, $60.86 \%$ were exon 19 mutations and $39.13 \%$ were exon 21 mutations ${ }^{[7]}$. Another study by Jain $\mathrm{D}^{[8]}$ et al, using both immunohistochemistry and PCR on 206 adenocarcinomas reported a prevalence of $26.6 \%$.Of the positive cases, $60 \%$ were exon 19 deletions and $40 \%$ were exon 21 point mutations. Comparing with these studies, we got a prevalence of $23 \%$ (23 mutations among 100 patients) by using immunohistochemistry alone. The frequency on the lower side in the present study can be explained by the method of detection that is IHC which detects only two most common mutations.(Exon 19 deletion and exon 21 point mutation)

Table 4: comparison between mutated and non mutated EGFR cases

\begin{tabular}{|c|c|c|c|}
\hline & $\begin{array}{l}\text { Non mutated } \\
\operatorname{EGFR}(n=81)\end{array}$ & $\begin{array}{c}\text { Mutated } \\
\text { EGFR(n=19) }\end{array}$ & $\begin{array}{l}\mathbf{P} \\
\text { value }\end{array}$ \\
\hline \multicolumn{3}{|l|}{ Age(in years) } & \multirow[b]{2}{*}{0.54} \\
\hline mean & 63.57 & 60.58 & \\
\hline \multicolumn{3}{|l|}{ Sex } & \multirow[b]{3}{*}{0.315} \\
\hline Male & $70(86 \%)$ & $18(95 \%)$ & \\
\hline Female & $11(14 \%)$ & $1(5 \%)$ & \\
\hline \multicolumn{3}{|l|}{ Smoking history } & \multirow[b]{3}{*}{0.226} \\
\hline Current or Ex smoker & $43(53 \%)$ & $13(68 \%)$ & \\
\hline Never smoker & $38(47 \%)$ & $6(32 \%)$ & \\
\hline \multicolumn{3}{|l|}{ Stage at presentation } & \multirow[b]{3}{*}{0.55} \\
\hline $1 \& 2$ & $17(21 \%)$ & $5(26 \%)$ & \\
\hline $3 \& 4$ & $64(79 \%)$ & $14(74 \%)$ & \\
\hline $\begin{array}{c}\text { Histological subtype } \\
\text { lepidic }\end{array}$ & $18(22 \%)$ & $6(32 \%)$ & \multirow[b]{4}{*}{0.006} \\
\hline acinar & $20(25 \%)$ & $11(57 \%)$ & \\
\hline Papillary & $5(6 \%)$ & 0 & \\
\hline Solid & $38(47 \%)$ & $2(10 \%)$ & \\
\hline
\end{tabular}


Previous studies $^{[7-10]}$ have reported a high prevalence of EGFR mutation in non smokers and in females. But in our study, no significant association was obtained between gender, smoking habitus and mutation status. The population of females were only $12 \%$ in our study and majority of the study population were smokers. Since no correlation between the presence of EGFR mutations and the stage of disease was found in this study EGFR mutation may be considered as an early event that plays an important role in the pathogenesis of lung adenocarcinoma.

We observed a significant association between histologic subtype and EGFR mutation status with a $\mathrm{p}$ value of $0.006(<0.05) .33 \%$ of the lepidic and $57 \%$ of the acinar subtypes showed EGFR mutation. This was in concordance with the previous studies ${ }^{[11]}$ which showed high rate of EGFR mutation in lepidic and acinar subtypes compared to less occurance of the mutation in papillary, micro papillary and solid subtypes.

\section{Photomicrographs}

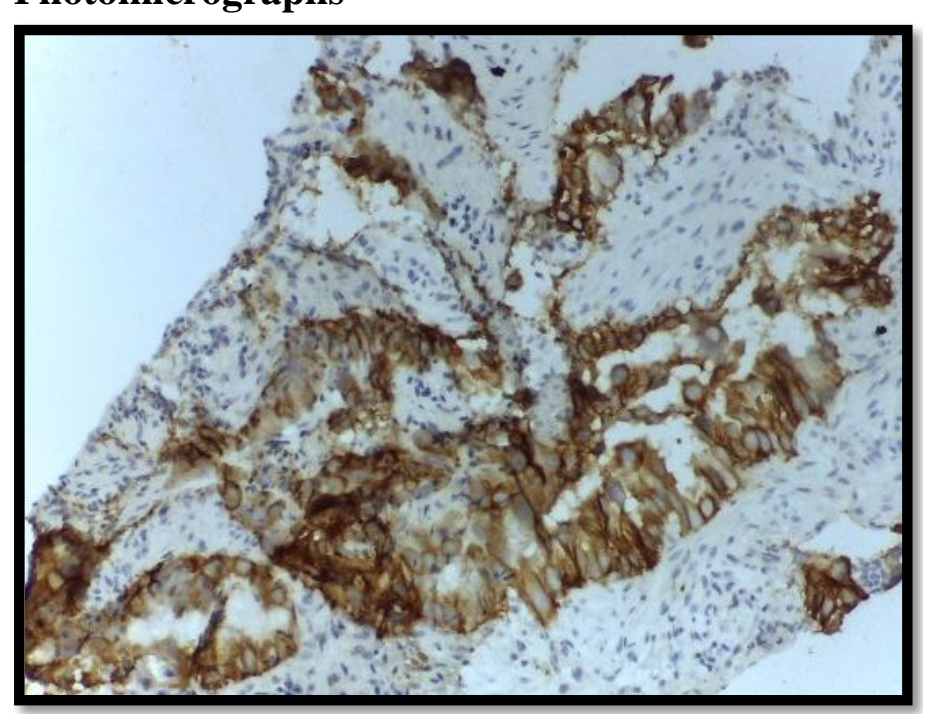

Figure 2: EGFR (L858R) (point mutation exon 21) IHC showing $3+$ membranous positivity (20X)

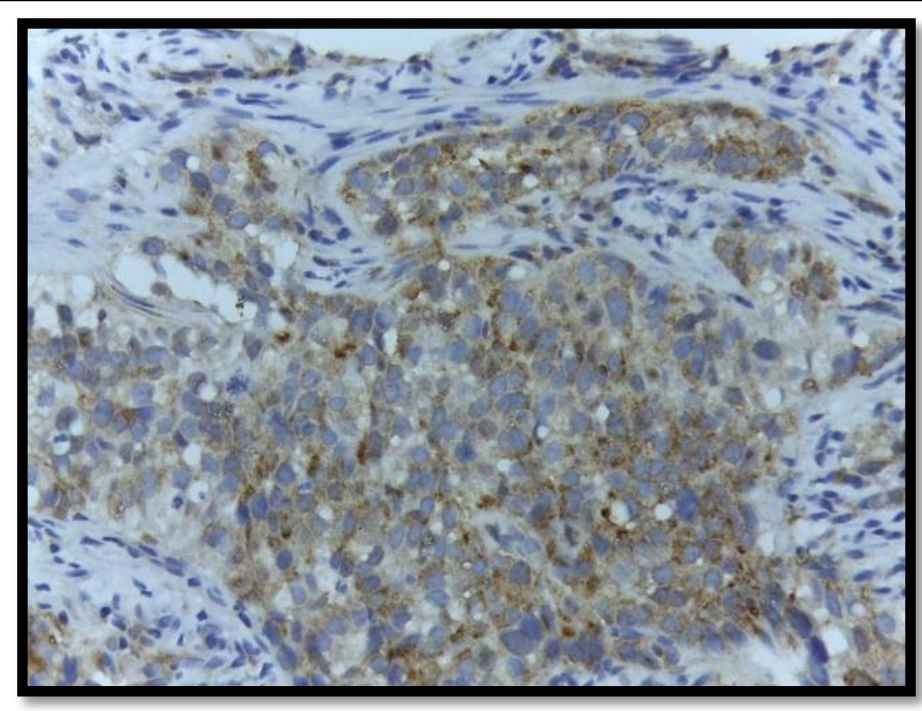

Figure 3: EGFR (E746-A750) (EXON 21 Point mutation) IHC showing 2+membranous and cytoplasmic positivity $(20 \mathrm{X})$

\section{Conclusion}

Epidermal Growth Factor Receptor over expression and mutation play an important role in the carcinogenesis of lung adenocarcinoma. Studies have shown that immunohistochemical (IHC) staining using epidermal growth factor receptor $(E G F R)$ mutation specific antibodies, is an easy and cost-effective, screening method compared with molecular techniques.

\section{Limitations}

One major drawback for the use of IHC to detect EGFR mutations is that these are specific only to their target mutations (E746-A750 deletion in exon 19 and L858R in exon 21). Other mutations such as TKI resistance exon 20 mutations cannot be detected by these two antibodies. However, it can be used as a screening tool especially in Indian setting.

\section{Acknowledgement}

I express my sincere gratitude to Dr Sathi P P,Dr Rajan G and Multidisciplinary Research Unit,Govt. Medical College, Kozhikode for their valuable guidance and help during this study.

\section{References}

1. Ferlay J, Soerjomatram I, Evik M, Dikshit $\mathrm{R}$, Eser S, Mathers C et al. GLOBACON 
2012 vl.0, Cancer Incidence and Mortality Worldwide: IARC Cancer Base No.11.Inernational Agency for Research on Cancer,Lyon,2014

2. Lynch TJ, Bell DW, Sordella R, et al. Activating mutations in the epidermal growth factor receptor underlying responsiveness of non-small-cell lung cancer to gefitinib. N Engl J Med 2004; 350:212939.

3. Shigematsu H, Lin L, Takahashi $\mathrm{T}$, et al. Clinical and biological features associated with epidermal growth factor receptor gene mutations in lung cancers. J Natl Cancer Inst 2005;97:339-346.

4. Kim HR, Shim HS, Chung JH, et al. Distinct clinical features and outcomes in neversmokers with nonsmall cell lung cancer who harbor EGFR or KRAS mutations or ALK rearrangement. Cancer 2012; 118:729-39.

5. Antonicelli A, Cafarotti S, Indini A, et al. EGFR-targeted therapy for non-small cell lung cancer: focus on EGFR oncogenic mutation. Int J Med Sci 2013; 10:320-30.

6. Cadranel J, Ruppert AM, Beau-Faller M, et al. Therapeutic strategy for advanced EGFR mutant non-small-cell lung carcinoma. Crit Rev Oncol Hematol 2013;88:477-93

7. Gaur P, Bhattacharya S, Surya Kant, Kushwaha RAS, Agarwal J and Pathak AK. Epidermal Growth Factor Receptor Mutations Detection by Mutant Specific Immunohistochemistry in North Indian Lung Cancer population. Int. J. Res. Dev. Pharm. L. Sci. 2017; 6(6): 2796-2799.

8. Deepali Jain,Sobuhi Iqbal et al. Evaluation of epidermal growth factor receptor mutations based on mutation specific immunohistochemistry in non-small cell lung cancer: A preliminary study Indian J Med Res. 2016 Mar; 143(3): 308-314

9. Dinesh C, Saud Azam, Ullas Batra et al. Epidermal growth factor receptor mutation in lung adenocarcinoma in India: A single centre

study.journal

of

carcinogenesis. 2013; 12: 12

10. Choughule A, Noronha V, Joshi A, Desai S, Jambhekar N, Utture S, et al. Epidermal growth factor receptor mutation subtypes and geographical distribution amongIndian non-small cell lung cancer patients. Indian J Cancer. 2013; 50:107-11.

11. Zhen Chen, Xiaoyan Liu, Jing Zhao, Y Hanjin, T Xiaodong. Correlation of EGFR mutation and histological subtype according to the IASLC/ATS/ERS classification of lung adenocarcinoma. Int $\mathbf{J}$ Clin Exp Pathol.2014:7(11):8039-8045. 